\title{
ARTICLE
}

\section{Male sexual dysfunction}

\author{
P Ramlachan, ${ }^{1} \mathrm{MB} \mathrm{ChB}, \mathrm{MHlthSc}, \mathrm{FECSM}$; M M Campbell, ${ }^{2} \mathrm{PhD}$ \\ ${ }^{1}$ Newkwa Medical Centre, Durban, South Africa \\ ${ }^{2}$ Department of Psychiatry and Mental Health, Faculty of Health Sciences, University of Cape Town, South Africa
}

Corresponding author: P Ramlachan (drprithy@newkwa.co.za)

Approximately $31 \%$ of men suffer from a sexual dysfunction in their lifetime. This review aims to provide the family practitioner with an approach to managing common cases of male sexual dysfunction, such as erectile dysfunction, using consensus guidelines.

S Afr Med J 2014;104(6):447. DOI:10.7196/SAMJ.8376

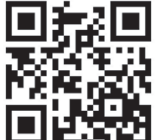

The US National Health and Social Life Survey (NHSLS) estimates that approximately $31 \%$ of men suffer from a sexual dysfunction in their lifetime. ${ }^{[1]}$ The aim of this review is to provide family practitioners with an approach to managing the common types of male sexual dysfunction.

\section{Method}

This review reflects the consensus and guidelines of the International Society of Sexual Medicine (ISSM), the recommendations of the International Consultation of Sexual Medicine-5 (ICSM-5), the Journal of Sexual Medicine and the guidelines of the European Association of Urology (EAU), the American Urological Association (AUA), the International Society for the Study of the Aging Male (ISSAM) and the Endocrinology Society. Our guidelines and recommendations aim to be evidence based and patient centred.

\section{Erectile dysfunction}

Erectile dysfunction (ED) and premature ejaculation are the two most common complaints of male patients presenting with sexual dysfunction. ${ }^{[2]}$ ED is defined as a man's consistent or recurrent inability to attain and/or maintain penile erection sufficient for satisfactory sexual activity. ${ }^{[3]}$ Symptoms include a marked difficulty in obtaining an erection during sexual activity and/or maintaining an erection until the completion of sexual activity, and a marked decrease in erectile rigidity.

\section{Epidemiology}

Globally, studies show a high prevalence ${ }^{[4-7]}$ and incidence of $\mathrm{ED},{ }^{[4,8,9]}$ correlating with general dissatisfaction, age and other sexual dysfunctions. ${ }^{[5,7]}$ In South Africa, an exploratory study at a primary healthcare clinic in KwaZulu-Natal demonstrated an overall prevalence of $64.9 \%(N=521)$ in a sample of men aged $\geq 18$ years. ${ }^{[10]} \mathrm{ED}$ increased with age, and showed a strong correlation with economic status and comorbid conditions.

\section{Clinical evaluation}

Up to $50 \%$ of men with ED also experience premature ejaculation (PE). ${ }^{[1]}$ Detailed history-taking that is sensitive to the patient's personal, cultural and ethnic background, and having the partner attend and engage in the clinical interview, assist in clarifying symptoms and refining the diagnosis.

\section{Assessment tools}

The International Index of Erectile Function-15 (IIEF-15) provides a domain score (IIEF-EF) for erectile function that has proven to be a reliable pretreatment screening tool and post-treatment response tool. ${ }^{[12]} \mathrm{A}$ recent study indicated that patients complaining of severe ED probably have other comorbid conditions. ${ }^{[13]}$ A more comprehensive medical assessment is recommended in these instances, regardless of the patient's age.

\section{Physical examination}

The physical examination (i) assists in corroborating aspects of the medical history; (ii) reveals unsuspected physical findings; (iii) assists in identifying specific aetiologies or comorbidities; and (iv) creates an opportunity to inform the patient about aspects of his sexual anatomy or physiology while providing reassurance about body appearance and function. ${ }^{[14]}$ However, the physical examination can be a source of shame, embarrassment, or discomfort for many and every effort should be made to ensure the patient's privacy, confidentiality and personal comfort.

\section{Treatment}

The primary goal is to enable the individual or couple to enjoy a satisfactory sexual experience. This involves (i) identifying and treating any curable causes of ED; (ii) initiating lifestyle change and risk factor modification; and (iii) providing education and counselling to patients and their partners. ${ }^{[15]}$ Medical treatments for ED include oral agents, local therapies and vacuum constriction devices. All patients with ED should be evaluated for testosterone levels before treatment begins.

\section{Oral agents}

Drugs that inhibit phosphodiesterase type 5 (PDE5) increase arterial blood flow, which leads to smooth muscle relaxation, vasodilation, and penile erection. Three potent selective PDE5 inhibitors have been approved and are available in South Africa - sildenafil (Viagra), tadalafil (Cialis), and vardenafil (Levitra). These medications are efficacious and safe, both in non-selected populations of men with ED and in specific subgroups. ${ }^{[16-18]}$ PDE5 inhibitors do not initiate erections, but require sexual stimulation to facilitate an erection. It is currently recommended that patients should receive 8 doses of a PDE5 inhibitor on demand, with sexual stimulation, before classifying the patient as a non-responder. ${ }^{[16-18]}$ Daily dosing with 
tadalafil $5 \mathrm{mg}$ has been approved for use in patients with $\mathrm{ED}$, and recently in those with ED and lower urinary tract symptoms, by the European Medicines Agency and the US Food and Drug Administration. PDE5 inhibitors are contraindicated in men using nitrates. ${ }^{[16-18]}$

\section{Local therapies}

Both intracavernosal injections and intraurethral alprostadil are effective and well tolerated and used as second-line therapies. ${ }^{[19]}$ Intracavernosal injections should not be used in men with conditions such as sickle cell disease, multiple myeloma and leukaemia, which predispose them to priapism.

Vacuum constriction devices are considered as first-line therapy by the British Society for Sexual Medicine. However, side-effects include painful ejaculation, inability to ejaculate, petechiae, bruising and numbness. ${ }^{[19]}$ Penile prostheses can be fitted in patients in whom medical therapy has failed or is contraindicated, or in whom other therapies have failed to satisfy the highly motivated patient.

\section{Psychotherapy}

Psychotherapy focuses on (i) reducing or eliminating performance anxiety; (ii) understanding the context in which men or a couple make love; (iii) implementing psychoeducation; and (iv) modifying sexual scripts, and identifying and reducing resistance to premature discontinuation of pharmacotherapy. ${ }^{[14]}$ While a variety of psychological interventions are available, efficacy and effectiveness studies are lacking.

\section{Erectile dysfunction and coronary artery disease}

ED and coronary artery disease share the same risk factors. ${ }^{[20]}$ While sexual activity for couples in a stable relationship does not increase cardiac events and sex is not an undue stress to the heart, men with ED should have their coronary artery disease risks assessed and treated. Sexual activity safety can be assessed using non-invasive stress testing, while exercise stress testing and computed coronary angiography can be used to detect occult coronary artery disease. The association between depression, ischaemic heart disease, and cardiovascular mortality has been well documented. ${ }^{[21]}$ Depression is also associated with sexual dysfunction and most frequently with ED. Therefore, irrespective of whether ED is a symptom or a cause of depression, a cardiac patient who is depressed is more likely to have ED (Fig. 1)

\section{Premature ejaculation}

The prevalence of $\mathrm{PE}$ is estimated at $24.9 \%{ }^{[22]}$ Lifelong $\mathrm{PE}$ is defined as ejaculation that 'always or nearly always occurs prior to or within about one minute of vaginal penetration', and/or 'the inability to delay ejaculation on all or nearly all vaginal penetrations', coupled with 'negative personal consequences such as distress, bother, frustration and/or the avoidance of sexual intimacy. ${ }^{[23]}$ PE may be the result of urological dysfunction, thyroid dysfunction or psychological and/or relationship problems. While most men with lifelong PE do not suffer from concomitant ED, PE coexists in about one-third of patients complaining of ED. ${ }^{[24]}$ All patients with PE must be carefully screened for ED. In some instances, $\mathrm{PE}$ and $\mathrm{ED}$ reduce a man's level of excitation (which can lead to ED), or a man trying to achieve an erection attempts to do so by increasing his excitation and arousal (which can lead to PE). PE may also occur when a man has an unstable erection because of a fluctuation in penile blood flow. In this case, the man may reach ejaculation quickly to compensate for the weak erection.

\section{Clinical evaluation}

Family practitioners should elicit details from the patient about the ejaculatory response, including his subjective assessment of his intravaginal ejaculatory latency time and sense of ejaculatory control. ${ }^{[14]}$ Furthermore, clinicians should enquire about the patient's level of sexual dissatisfaction, distress, and frequency of sexual activity. Included in this evaluation should be the partner's assessment of the patient's complaint and whether the partner suffers from sexual dysfunction. It is important to note that ejaculation is not equal to orgasm.

\section{Treatment}

All symptomatic therapies for PE aim to reduce excitation. Therefore, these treatments must be prescribed to patients who are able to obtain and maintain an erection until their (premature) ejaculation.

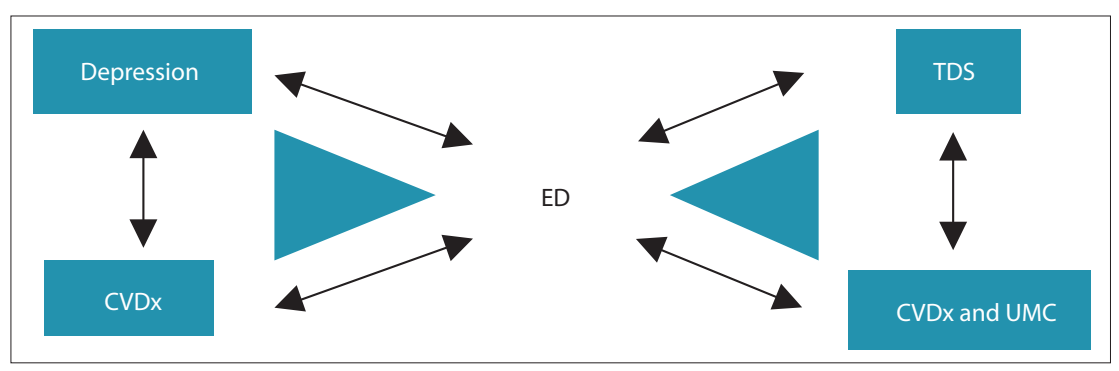

Fig. 1. The link between erectile dysfunction (ED), depression, testosterone deficiency syndrome (TDS), cardiovascular diagnosis (CVDx) and underlying metabolic conditions (UMC).
The efficacy and safety of off-label daily dosing with selective serotonin re-uptake inhibitors (SSRIs) (paroxetine, sertraline, citalopram and fluoxetine), ${ }^{[25]}$ the serotonergic tricyclic clomipramine, and off-label on-demand dosing with clomipramine for the treatment of PE are well established. ${ }^{[26]} \mathrm{A}$ meta-analysis of published data suggests that paroxetine exerts the strongest ejaculation delay. ${ }^{[27]}$ Recently, dapoxetine (a short-acting SSRI) has been officially approved in Europe and some other countries for on-demand treatment of PE. ${ }^{[28]}$ The efficacy and safety of off-label on-demand topical anaesthetic agents have also been demonstrated. ${ }^{[29]}$ However, there is currently no evidence to suggest that selective dorsal nerve neurotomy or hyaluronic acid gel glans penis augmentations are effective treatments for PE. ${ }^{[14]}$ Surgery, which may be associated with permanent loss of sexual function, is contraindicated.

\section{Psychotherapy}

Besides teaching self-control techniques to delay ejaculation, psychosexual therapies attempt to help the patient to recover his self-confidence and confidence in his sexual performance, reduce performance anxiety, solve rational problems, increase communication between partners, and resolve interpersonal issues that precipitate and maintain the dysfunction. ${ }^{[14]}$ However, efficacy and effectiveness studies are lacking.

\section{Orgasmic dysfunction}

Orgasmic dysfunction (OD) is the inability to achieve an orgasm or the markedly diminished intensity of an orgasm. ${ }^{[2,14]}$ It can also be the marked delay of orgasm during any kind of sexual stimulation. Delayed ejaculation, retarded ejaculation, and inhibited ejaculation are probably the least common, least studied, and least understood male sexual dysfunctions. ${ }^{[14]}$

\section{Clinical evaluation}

Treatment should be aetiology specific and should address infertility in men of a

\section{Oral agents}


reproductive age. Assessment begins by reviewing the conditions under which a man is able to ejaculate (e.g. during sleep, masturbation, stimulation by partner). If orgasmic attainment had been possible previously, the life events and circumstances temporarily related to orgasmic cessation are reviewed. ${ }^{[14]}$ The events in question may be pharmaceutical or related to congenital problems, illness, trauma, or a variety of life stressors and other psychological factors, influenced further by societal and religious attitudes.

\section{Treatment}

Regardless of whether a clear pathophysiological cause is present/ absent, patients may be counselled to consider lifestyle changes including enjoying more time together to achieve greater intimacy, minimising alcohol consumption, making love when not tired and practising techniques that maximise penile stimulation, such as pelvic floor training. ${ }^{[14]}$ Patient education regarding existing factors that can exacerbate OD is an important first step and may represent a segue into counselling. Treatment with pharmaceuticals has had limited success. ${ }^{[14]}$ No drugs have been approved by regulatory agencies for this purpose.

\section{Male hypoactive sexual desire disorder} Male hypoactive sexual desire disorder is defined as persistently or recurrently deficient (or absent) sexual/erotic thoughts or fantasies and desire for sexual activity. ${ }^{[2,3]}$ This may be the result of common medical conditions including substance-use disorders, social and interpersonal factors, or use of pharmacological agents. ${ }^{[3]}$

\section{Clinical evaluation}

A comprehensive history should address the patient's sexual behaviour, psychological manifestations of sexual stimuli and body changes in response to sexually arousing stimuli. ${ }^{[31]}$ Laboratory investigations should determine the patient's serum testosterone and prolactin levels.

\section{Treatment}

Treatment should focus initially on targeting and treating sexual difficulties, e.g. pain and ED. ${ }^{[30]}$ Furthermore, the clinician should assess the patient-partner relationship and teach sexual communication and erotic skills. Finally, the clinician should attempt to maximise enhancers (e.g. varied lovemaking, novelty) and reduce inhibitors (both physical, e.g. anaemia and thyroid disease, and emotional, e.g. anxiety and depression). Testosterone replacement therapy may be considered in some cases.

\section{Conclusion}

In male sexual dysfunction there are times when psychiatric care should be considered, particularly in patients with severe depression, substance-use disorders, or abusive and chaotic relationships. Objective evidence does not support the use of natural aphrodisiacs as an effective treatment for male or female sexual dysfunctions. ${ }^{[32]}$ There is, however, a growing database of evidence-based treatments for male sexual dysfunctions.

\section{Future treatments for erectile dysfunction}

- New PDE5 inhibitors (e.g. Udenafil, Avanafil, Mirodenafil)

- Topical alprostadil cream (Topiglan)

- Melanocortin activators.

\section{Take-home messages}

- ED shares risk factors with cardiovascular disease.

- 'The recognition of ED as a warning sign of silent vascular disease has led to the concept that a man with ED and no cardiac symptoms is a cardiac (or vascular) patient until proven otherwise. ${ }^{[33]}$

- Clinical use of validated questionnaires addressing ED may be helpful.

- Lifestyle changes and risk factor modification should precede or accompany ED treatment.

- PDE5 inhibitors are contraindicated in patients using nitrates.

- PE is more common than ED.

- Patients must be advised that SSRI treatment for PE is off-label.

\section{References}

1. Laumann EO, Paik A, Rosen RC. Sexual dysfunction in the United States: Prevalence and predictors. JAMA 1999;281(6):537-544. [http://dx.doi.org/10.1001/jama.281.6.537]

2. Lindau ST, Schumm LP, Laumann EO, et al. A study of sexuality and health among older adults in the United States. N Engl J Med 2007;357(8):762-774. [http://dx.doi.org/10.1056/NEJMoa067423]

3. American Psychiatric Association. The Diagnostic and Statistical Manual of Mental Disorders. 5th ed American Psychiatric Association. The Diagnostic and
Washington, DC: American Psychiatric Association, 2013.

4. Feldman HA, Goldstein I, Hatzichristou DG, et al. Impotence and its medical and psychosocial correlates: 4. Feldman HA, Goldstein I, Hatzichristou DG, et al. Impotence and its
Results of the Massachusetts Male Aging Study. J Urol 1994;51(1):54-61.

5. Braun M, Wassmer G, Klotz T, et al. Epidemiology of erectile dysfunction: Results of the 'Cologne Male Survey'. Int J Impot Res 2000;12(6):305-311. [http://dx.doi.org/10.1038/sj.ijir.3900622]

6. Hwang TI, Tsai TF, Lin YC, et al. A survey of erectile dysfunction in Taiwan: Use of the erection hardness score and quality of erection questionnaire. J Sex Med 2010;7(8):2817-2824. [http://dx.doi.org/10.1111/j.17436109.2010.01837.x]

7. Amidu N, Owiredu WK, Woode E, et al. Prevalence of male sexual dysfunction among Ghanaian populace: Myth or reality? Int J Impot Res 2010;22(6):337-342. [http://dx.doi.org/10.1038/ijir.2010.24]

8. Moreira ED Jr, Lbo CF, Diament A, et al. Incidence of erectile dysfunction in men 40 to 69 years old: Results from a population-based cohort study in Brazil. Urology 2003;61(2):431-436. [http://dx.doi.org/10.1016/ S0090-4295(02)02158-1]

9. Schouten BW, Bosch JL, Bernsen RM, et al. Incidence rates of erectile dysfunction in the Dutch general population. Effects of definition, clinical relevance and duration of follow-up in the Krimpen Study. Int J Impot Res 2005;17(1):58-62. [http://dx.doi.org/10.1038/sj.ijir.3901264]

10. Lockhat $\mathrm{Y}$, Ross $\mathrm{A}$, Ramlachan $\mathrm{P}$, Rangiah $\mathrm{C}$. The prevalence of erectile dysfunction at a primary healthcare clinic in Durban, KwaZulu-Natal. S Afr Fam Pract 2013;55(3):289-293.

11. Corona G, Petrone L, Mannucci E, et al. Psycho-biological correlates of rapid ejaculation in patients attending an andrological unit for sexual dysfunctions. Eur Urol 2004;46:615-622. [http://dx.doi.org/10.1016/j. eururo.2004.07.001]

12. Cappellleri JC, Siegal RL, Osterloh IH, Rosen RC. Relationship between patient self assessment of erectile function and the erectile function domain of the International Index of Erectile Function. Urology function and the erectile function domain of the International Index
2000;58(3):477-481. [http://dx.doi.org/10.1016/S0090-4295(00)00697-X]

13. Salonia A, Castagna G, Sacca A, et al. Is erectile dysfunction a reliable proxy of general male health status? The case for the International Index of Erectile Function-Erectile function domain. J Sex Med 2012;9:2708-2715. [http://dx.doi.org/10.1111/j.1743-6109.2012.02869.x]

14. Montorsi F, Adaikan G, Becher E, et al. Summary of the recommendations on sexual dysfunctions in men. J Sex Med 2010;7:3572-3588. [http://dx.doi.org/ 10.1111/j.1743-6109.2010.02062.x]

15. European Association of Urology. European Association of Urology 2013 Guidelines on Male Sexual Dysfunction. http://www.europeanurology.com/eau-guidelines (accessed 21 February 2014).

16. Lilly, UK SPC for Cialis. 2006. http://www.lilly.co.uk (accessed 21 February 2014).

17. Bayer, UK SPC for Levitra. 2006. http://www.bayer.co.uk (accessed 21 February 2014).

18. Pfizer, UK SPC for Viagra. 2006. http://www.pfizer.co.uk (accessed 21 February 2014).

19. Hackett G, Kell P, Ralph D, et al. for the British Society for Sexual Medicine. British Society for Sexual Medicine guidelines on the management of erectile dysfunction. J Sex Med 2008;5:1841-1865. [http://dx.do org $/ 10.1111 / j .1743-6109.2008 .00773 . x]$

20. Guo W, Liao C, Zou Y, et al. Erectile dysfunction and risk of clinical cardiovascular events: A meta-analysis of seven cohort studies. J Sex Med 2010;7(8):2805-2816. [http://dx.doi.org/10.1111/j.1743-6109.2010.01792.x]

21. El-sakka AI. Erectile dysfunction, depression, and ischemic heart disease: Does the existence of one componen of this triad necessitate inquiring the other two? J Sex Med 2011;8:937-940. [http://dx.doi.org/10.1111/j.17436109.2011.02231.x]

22. Porst $\mathrm{H}$, Montorsi F, Rosen RC, et al. The Premature Ejaculation Prevalence and Attitudes (PEPA) survey: Prevalence, comorbidities, and professional help-seeking. Eur Urol 2007;51:816-824. [http://dx.doi. Prevalence, comorbidities, and
org/10.1016/j.eururo.2006.07.004]

23. McMahon CG, Althof SE, Waldinger MD, et al. An evidence-based definition of lifelong premature ejaculation: Report of the International Society for Sexual Medicine (ISSM) ad hoc committee for the definition of premature ejaculation. J Sex Med 2008;5:1590-1606. [http://dx.doi.org/10.1111/j.1743-6109.2008.00901.x]

premature ejaculation. J Sex Med 2008;5:1590-1606. [http://dx.doi.org/10.1111/j.1743-6109.2008.00901.x
24. Fugl-Meyer K, Fugl-Meyer AR. Sexual disabilities are not singularities. Int J Impot Res 2002;14:487-493.

24. Fugl-Meyer K, Fugl-Meyer AR. Sexual disabilities are not singularities. Int J Impot Res 2002;14:487-493.
25. Wang WF, Chang L, Minhas S, Ralph DJ. Selective serotonin reuptake inhibitors in the treatment of premature ejaculation. Chin Med J 2007;120:1000-1006.

26. Haensel SM, Rowland DL, Kallan KT. Clomipramine and sexual function in men with premature ejaculation and controls. J Urol 1996;156(4):1310-1315. [http://dx.doi.org/10.1016/S0022-5347(01)65576-9]

27. Hatzichristou D, Rosen RC, Broderick G, et al. Clinical evaluation and management strategy for sexual dysfunction in men and woman. J Sex Med 2004;1:49-57. [http://dx.doi.org/10.1111/j.1743-6109.2004.10108.x] 28. Buvat J, Tesfaye F, Rothman M, et al. Dapoxetine for the treatment of premature ejaculation: Results from a randomized, double-blind, placebo-controlled phase 3 trial in 22 countries. Eur Urol 2009;55:957-967. [http:// dx.doi.org/10.1016/j.eururo.2009.01.025]

29. Morales A, Barada J, Wyllie MG. A review of the current status of topical treatments for premature ejaculation BJU Int 2007;100(3):493-501. [http://dx.doi.org/10.1111/j.1464-410X.2007.07051.x]

30. Maurice WL. Sexual Medicine in Primary Care. 1st ed. Canada: Mosby, 1999:159-188.

31. Meuleman EJH, Van Lankveld JJDM. Hypoactive sexual desire disorders: An underestimated condition in men. BJU Int 2005;95(3):291-294. [http://dx.doi.org/10.1111/j.1464-410X.2005.05285.x]

32. Shamloul R. Natural aphrodisiacs. J Sex Med 2010;7:39-49. [http://dx.doi.org/10.1111/j.1743-6109.2009.01521.x]

33. Jackson G, Rosen RC, Kloner RA, Kostis JB. The second Princeton consensus on sexual dysfunction and cardiac risk: New guidelines for sexual medicine. J Sex Med 2006;3(1):28-36. [http://dx.doi.org/10.1111/j.17436109.2005.00196.x] 